\title{
O termo práticas corporais na literatura científica brasileira e sua repercussão no campo da Educação Física
}

\author{
Ari Lazzarotti Filho* \\ Ana Marcia Silva* \\ Priscilla de Cesaro Antunes ${ }^{* * *}$ \\ Ana Paula Salles da Silva*** \\ Jaciara Oliveira Leite ${ }^{* * * * *}$
}

\begin{abstract}
Resumo: Objetivou-se identificar os significados/sentidos com os quais o termo práticas corporais vem sendo utilizado na literatura acadêmica brasileira, mediante análise de conteúdo de 260 artigos e 17 teses/dissertações, capturados com o uso de palavras-chave em sistemas de busca e bases de dados. Os resultados indicam que: sua utilização intensifica-se a partir do ano 2000; os pesquisadores que o utilizam, predominantemente, desenvolvem suas pesquisas na interface com as humanidades; na maioria dos documentos não há uma preocupação de definição conceitual; apresenta vários significados/sentidos. Os dados indicam ainda não ter atingido estabilidade como conceito, apesar de estar acumulando elementos para tal.

Palavras-chave: Técnicas de Exercício e de Movimento. Educação Física. Formação de Conceito.
\end{abstract}

\section{INTRODUÇÃo / JustiFICATIVA}

A Educação Física, em sua configuração como campo acadêmico, pode ser considerada recente, ao ser comparada a outros cam-

* Doutorando no Programa de Pós-Graduação da Universidade Federal de Santa Catarina. Professor da Faculdade de Educação Física da Universidade Federal de Goiás, Goiânia, GO, Brasil. E-mail: arilazzarotti@gmail.com

** Professora do Programa de Pós-Graduação da Universidade Federal de Santa Catarina e da Faculdade de Educação Física da Universidade Federal de Goiás, Goiânia, GO, Brasil. E-mail: amarciasi@gmail.com

*** Mestranda do Programa de Pós-Graduação da Universidade Federal de Santa Catarina, Florianópolis, SC, Brasil. E-mail: pri2602@hotmail.com

**** Doutoranda no Programa de Pós-Graduação da Universidade Federal de Santa Catarina. Professora da Faculdade de Educação Física da Universidade Federal de Goiás - Campus Catalão, Goiânia, GO, Brasil. E-mail : aninhasalless@msn.com

***** Mestranda do Programa de Pós-Graduação da Universidade Federal de Santa Catarina. Florianópolis, SC, Brasil. E-mail: jacifef1@yahoo.com.br 
pos do conhecimento. Sua produção de conhecimento apresenta-se dispersa, tal como a socialização deste, em certa medida, pulverizada por diferentes campos com os quais estabelece interface. Poucas são as aproximações teórico-metodológicas no interior desta comunidade acadêmica, situação que amplia a necessidade de consensos mínimos em torno de conceitos chave, em busca de atingir maior estabilidade na produção acadêmica.

Tal estabilidade possibilitaria um avanço na direção de ampliar a comunicação entre pesquisadores e grupos de pesquisa com objetivos afins, intenção que começa a tornar-se mais presente em seu debate interno. Segundo Fensterseifer (2008), essa necessidade somente nos assola enquanto campo acadêmico-profissional por termos nos colocado pretensões de maioridade, o que parece indicar certa positividade neste processo interno de diálogo, revisão e autocrítica.

Há que se considerar, também, a necessidade crescente da qual a Educação Física vem se ressentindo, que diz respeito ao uso de palavras-chave, descritores os quais são solicitados e, em alguma medida, previamente determinados pelos periódicos e eventos científicos. Os descritores requeridos apresentam-se como uma rede semântica que traz dificuldades, sobretudo, para a parcela do campo da Educação Física que trabalha na interface com as humanidades. Isso porque a grande maioria dos termos indicados, mais de $80 \%$ deles, no caso dos Descritores em Ciências da Saúde (DeCS), foram constituídos no campo da Medicina e instituem uma estrutura hierárquica interna.

Os descritores constituem-se como termos ou áreas reconhecidos mais amplamente e expressam um movimento importante no sentido de permitirem uma possibilidade de trabalho e diálogo entre a comunidade científica internacional. Apesar disso, tendem a cristalizar uma concepção de atividade científica e de objeto de pesquisa que mereceria uma reflexão mais aprofundada. Tornou-se um desafio, porém, que campos como o da Educação Física não poderão deixar de enfrentar, sob pena de verem aumentadas, ainda mais, suas dificuldades de produção e divulgação do conhecimento.

Uma análise inicial da produção acadêmica deste campo mostra uma grande diversidade de termos e conceitos operados com sentidos

Movimento, Porto Alegre, v. 16, n. 01, p. 11-29, janeiro/março de 2010. 
distintos e, por vezes, contraditórios. Tal situação pode ser compreendida ao considerarmos que sua constituição foi ditada pelas necessidades de intervenção profissional, sobretudo como disciplina curricular do sistema oficial de ensino, bem como nos diferentes interesses e usos institucionais aos quais a Educação Física vem estando vinculada.

Constituiu-se ao longo de sua história, no diálogo com a filosofia e as ciências humanas e sociais, assim como com as ciências exatas, a cultura popular e a arte, ainda que a maior ênfase no Brasil recaia nas ciências biológicas e exatas, uma trajetória constituída nas fronteiras do conhecimento (VAZ, 2000). Talvez, como desdobramento desse processo, seus conceitos ainda encontrem-se em fase de consolidação e precisem ser mais bem elaborados, inclusive para facilitar a comunicação de sua comunidade acadêmica e desta com a sociedade. Citamos aqui profícuas iniciativas que resultaram em publicações, como o Dicionário Crítico da Educação Física (GONZÁLEZ; FENSTENSEIFER, 2005), o Dicionário do Esporte (MELO, 2007) e o Dicionário do Lazer (GOMES, 2004), as quais trazem à tona alguns conceitos para avanços do campo.

Uma parcela deste desafio que buscamos enfrentar parte da compreensão de que o termo práticas corporais vem sendo crescentemente utilizado, tanto no âmbito das pesquisas acadêmicas quanto no de documentos oficiais, ${ }^{1}$ fazendo-se presente inclusive em revistas comerciais ${ }^{2}$ de grande circulação nacional. Ao analisarmos o termo com maior cautela, identificamos seu uso com diferentes significados/sentidos, ${ }^{3}$ os quais se remetem a distintos referentes ou signos.

A partir desta problemática, este estudo objetivou identificar quais os significados/sentidos com os quais o termo práticas corporais vem sendo utilizado pela literatura acadêmica brasileira. Para tal, partimos

\footnotetext{
${ }^{1}$ Referimos-nos à Política Nacional de Promoção da Saúde (2006) e aos Parâmetros Curriculares Nacionais de Educação Física para o Ensino Fundamental (1997).

2 Estamos nos referindo à Revista Nova Escola, São Paulo, v. 22, n. 213 jun./jul. 2008.

${ }^{3}$ Ao analisar os diferentes processos de operacionalização do termo práticas corporais, entendemos "significado/sentido" na perspectiva de Smolka (2000, p. 29) como parte de "produção simultânea de signos e sentidos, relacionada à constituição de sujeitos, na dinâmica dessas (inter-)relações [...], diferentes valores, diferentes significados, diferentes sentidos emergem na diversidade dessas elaborações".

Wovimento, Porto Alegre, v. 16, n. 01, p. 11-29, janeiro/março de 2010.
} 
da hipótese de que o mesmo constitui-se a partir do contraste com o conceito de atividade física e ainda carece de elementos mais consistentes para sua conceituação.

\section{A ESPECIFICIDADE DO CAMPO DA EDUCAÇÃo FísICA}

A especificidade da Educação Física tem sido amplamente discutida desde a década de 1990 (TANI, 1996; BETTI, 1996; LOVISOLO, 1998; BRACHT, 1999; FERREIRA NETO, 2005). Em função de sua constituição e trajetória, a todo o momento surgem novas questões e desdobramentos, os quais, por sua vez, exigem novas soluções e encaminhamentos.

A Educação Física no Brasil foi constituída, essencialmente, como disciplina escolar, ainda que subordinada a outras instituições como a médica, a militar e a esportiva. Foi, porém, como componente curricular que a Educação Física ganhou legitimidade social para consolidar-se no campo acadêmico, ainda que em busca de autonomia (PAIVA, 2004). Para Bracht (2003), foi a partir da década de 1970 que o campo acadêmico da Educação Física começa a incorporar cada vez mais intensamente as práticas científicas, determinando a criação de entidades científicas próprias, a realização de eventos científicos, a criação de cursos de pós-graduação e a definição de programas de apoio à pesquisa.

A pós-graduação em Educação Física no Brasil foi criada em 1977 em nível de Mestrado e em 1989 em nível de doutorado, fundamentalmente, pelo retorno dos professores que desenvolveram seus cursos de pós-graduação na América do Norte e na Europa, acrescido daqueles que desenvolveram seus cursos no país, em outros campos do conhecimento como saúde e educação.

A sua constituição como campo acadêmico, o ingresso no sistema de pós-graduação nacional, a sua instalação na área 21 da CAPES, vinculada ao ramo das ciências da vida e à grande área da saúde, trazem novos problemas nas formas de fazer ciência e na constituição de sua especificidade. O enquadramento da Educação Física na Grande Área da Saúde-CAPES traz consigo outros desdobramentos e talvez o mais significativo seja a forma de operar a produção do

Wovimento, Porto Alegre, v. 16, n. 01, p. 11-29, janeiro/março de 2010. 
conhecimento nesta área, visto que é uma das pioneiras no fazer ciência, com grande acúmulo e estabilidade conceitual, delegando a um campo novo (educação física) um alto nível de exigência quantitativa e qualitativa, com um enquadramento severo de produção científica e de sua comunidade acadêmica (SILVA, 2007).

No âmbito da comunidade acadêmica da Educação Física, o problema não é considerado como resolvido, tal como pretende a política científica oficial, pois há avaliações de que "estamos" nas ciências da saúde e não "somos" das ciências da saúde, ao menos, não "apenas" das ciências da saúde. Este encaminhamento oficial tem grandes consequências para o campo, pois no interior das ciências da saúde há uma larga hegemonia da lógica das ciências biológicas. Sua forma de produzir conhecimento acaba desconsiderando e, de certa forma, criando obstáculos à relação estreita que este campo estabelece com as ciências humanas e sociais, em especial, com a educação. Acerca desta questão, Mugnaini e Población (2007), ao analisarem a forma como vários campos operam na produção do conhecimento, reforçam a perspectiva de que são diferentes as formas de produzir e validar estes conhecimentos nas diferentes áreas.

Num campo acadêmico onde a linguagem é especializada, os conceitos são fundamentais para o avanço e para o desenvolvimento do próprio processo de conhecimento, facilitando o diálogo a partir de representações comuns e da recuperação deste para novas gerações.

Para operar nesta perspectiva, o conceito é fundamental; é a unidade de conhecimento que surge pela síntese dos predicados necessários e relacionados com determinado objeto e que, por meio de sinais linguísticos, pode ser comunicado aos demais, o que exige que a linguagem especializada tenha maior precisão do que aquela do senso comum.

Na perspectiva de Dahlberg (2006 apud CAMPOS; SOUZA; CAMPOS, 2003, p. 11), o conceito é formado por três elementos: o referente (aquilo que se pretende conceituar), as características (soma dos enunciados verdadeiros sobre o referente) e a forma verbal constituindo o triângulo conceitual. Deste modo, o conceito deixa de ser meramente um artefato mental e abstrato para instrumentalizar

Movimento, Porto Alegre, v. 16, n. 01, p. 11-29, janeiro/março de 2010. 
a linguagem e ser manipulado para a construção de vocabulários e tesauros.

Um termo, ao contrário da palavra, deve ser contextualizado no discurso, tendo, consequentemente, um referente de interpretação. Le Guern (1989) sugere que a palavra, unidade do léxico, constitui um predicado livre e o termo, unidade do discurso, um predicado vinculado. De qualquer modo, uma definição não é única, mas varia conforme a fonte, razão pela qual fazer uma definição equivale a estabelecer uma "equação de sentido", limitá-la de algum modo, para fixar os limites de um conceito ou ideia (DAHLBERG, 1978).

Essa equação não é simples, haja vista a diversidade das áreas de conhecimento. Para Krieger (2006), as novas áreas científicas e tecnológicas, como também as humanidades e ciências sociais aplicadas, têm sua terminologia distante das ciências de natureza taxionômica, confundindo-se muitas vezes com o léxico comum da língua, fato que é confirmado pelo crescimento dos sentidos terminológicos nos verbetes dos dicionários de língua comum.

Aqui, encontra-se um dilema central da Educação Física como campo acadêmico que estabelece relação tanto com as áreas mais "duras" (ciências biológicas) quanto com as áreas mais "moles" (ciências humanas). De um lado, exigindo uma conceituação mais rigorosa nos termos de tesauros e descritores e do outro, ampliando seus sentidos e possibilidades de constituição de objetos de pesquisa.

\section{DOS PROCEDIMENTOS METODOLÓGICOS DA PESQUISA}

Para atingir os objetivos desta pesquisa, nos apropriamos de metodologias de tipo quanti-qualitativo, com especial atenção para a análise de conteúdo. Seguindo as etapas definidas por Bardin (1979), préanálise, descrição analítica e interpretação referencial. A pesquisa se desenvolveu por meio da junção dos documentos a serem analisados; leitura preliminar; organização dos dados por aproximações e distanciamentos; descrição analítica das bases essenciais encontradas nos documentos e organização de um procedimento lógico-dialético e organização das categorias explicativas forjadas a partir dos documentos analisados em tensão com a base teórica conceitual.

Movimento, Porto Alegre, v. 16, n. 01, p. 11-29, janeiro/março de 2010. 
Como técnica de coleta de dados, foi utilizada a busca do termo "práticas corporais" com o filtro da língua portuguesa-Brasil na rede mundial de computadores. Justifica-se a escolha desta língua pelo fato da comunidade acadêmica brasileira produzir e publicar maciçamente em periódicos nacionais, ainda que seja um interessante exercício acadêmico fazer a busca com a tradução deste termo em outras línguas, notadamente a espanhola, na qual o uso deste termo é frequente, especialmente entre países latino-americanos.

A recuperação dos documentos e sua análise ocorreram a partir da "regra da exaustividade" (BARDIN, 1979), em que todos os documentos acadêmicos que mencionam o termo "práticas corporais" em artigos científicos, teses e dissertações foram selecionados e agrupados em categorias. Esse processo constitui-se da seguinte forma:

a) Para periódicos: primeiramente, foi feita uma pesquisa ampla com o termo "práticas corporais" nos seguintes sistemas de buscas: Google acadêmico; Scielo; Lilacs; Medline. Os artigos foram selecionados manualmente a partir dos critérios: permitir acesso online ao texto na íntegra e ser publicado em periódicos científicos com conselho editorial. $^{4}$

b) Para teses e dissertações: o termo "práticas corporais" foi inserido no sistema de busca do Banco de Teses e Dissertações (BTDT) Os documentos analisados foram os que permitiram acesso online ao texto na íntegra. ${ }^{5}$

A partir deste procedimento, chegou-se a um universo de 17 teses e dissertações e 260 artigos publicados em diversos periódicos. Para a sistematização dos dados, foi elaborada uma planilha onde cada documento selecionado teve suas informações descritas em detalhes como: acesso; natureza do documento; título; autor; área; ano de publicação; número de ocorrências do termo; conceito; autor referência; tema/eixo aglutinador.

${ }^{4}$ Procedimento realizado entre 08 de agosto e 15 de outubro de 2008.

${ }^{5}$ Procedimento realizado entre 20 de setembro e 15 de outubro de 2008.

Wovimento, Porto Alegre, v. 16, n. 01, p. 11-29, janeiro/março de 2010. 
Ari Lazzarotti Filho et al.

\section{APRESENTAÇÃO DOS DADOS}

\subsection{Periódicos Científicos}

Dentre o material analisado, o termo "práticas corporais" aparece pela primeira vez em artigo de autoria de Fraga (1995) e passa a ser mais utilizado a partir de 1996. Ao verificar o ano de publicação dos textos recuperados, identificamos que $86 \%$ situam-se entre os anos 2000 e 2008 e $14 \%$ entre 1990 e 1999 , mostrando-nos, com as devidas ressalvas, que o termo vem sendo utilizado com maior frequência e ganhando maior relevância acadêmica com o passar dos anos.

Os artigos recuperados e analisados, em número de 260, encontram-se $67 \%$ publicados em periódicos do campo da Educação Física; 7,7\% na Educação; 4,6\% na Antropologia; 4,2\% na Saúde; 4,2\% na Psicologia; $3,8 \%$ em periódicos de origem multidisciplinar; $3 \%$ na História; $1,9 \%$ nas Ciências da Comunicação; 1,5\% nas Ciências Sociais e $1,1 \%$ na Sociologia. Observa-se, portanto, que o campo da Educação Física é o que mais opera com o termo, ao menos quando se trata dessa modalidade de divulgação científica. Identificamos, também, que os artigos analisados e os respectivos periódicos de onde provêm, quando utilizam o termo, fazem-no estabelecendo uma relação mais próxima com as ciências humanas e sociais. Inclusive os artigos provenientes de revistas do campo da saúde, quando o utilizam, vinculam-se às ciências humanas e sociais em seus argumentos teóricos, em especial no interior de subáreas como a saúde coletiva.

Dos 260 artigos analisados, verificamos que a grande maioria não explicita o entendimento de práticas corporais e somente $8 \%$ o fazem. Dentre aqueles artigos que apresentam explicitamente a conceituação, identificamos os seguintes elementos argumentativos:

1. São identificadas como manifestações culturais que enfocam a dimensão corporal, característica, segundo os textos analisados, não presente na perspectiva dos pesquisadores que utilizam o conceito de atividade física;

2. Buscam superar a fragmentação identificada na constituição do ser humano e denotam uma crítica à forma de organização da vida contemporânea e seus desdobramentos no corpo;

Movimento, Porto Alegre, v. 16, n. 01, p. 11-29, janeiro/março de 2010. 
3. Apontam para uma ampliação conceitual deste termo com elementos das ciências humanas e sociais e tensionam com uma concepção de ciência pautada na objetividade e neutralidade;

4. Exemplificadas, principalmente, como esporte, ginástica, dança, luta, tai-chi, yoga, práticas de aventura, jogos;

5. Destacam-se as diferenças e contrastes entre as práticas corporais orientais e as ocidentais;

6. Externam uma preocupação com os significados/sentidos atribuídos às práticas corporais por parte dos sujeitos que as praticam, para além de sua utilidade mais pragmática;

7. Apresentam finalidades como promoção da saúde, educação para sensibilidade, para estética, para desenvolvimento do lazer e para o cuidado com o corpo.

Nos demais artigos (92\%), não há uma conceituação explícita, mas os significados/sentidos atribuídos às práticas corporais podem ser agrupados nos seguintes temas/eixo:

\begin{tabular}{|l|c|c|}
\hline \multicolumn{1}{|c|}{ Temas/Eixo } & Frequência & \% \\
\hline Termo dado & 188 & 72,6 \\
\hline Diferente de esporte & 20 & 7,7 \\
\hline Alternativas & 15 & 5,8 \\
\hline Adjetivos diversos & 14 & 5,4 \\
\hline Cultura corporal & 9 & 3,5 \\
\hline Cotidiano & 6 & 2,3 \\
\hline Esporte & 5 & 1,9 \\
\hline Atividade física & 2 & 0,8 \\
\hline
\end{tabular}

Tabela 1 - Temas/Eixo para análise do termo práticas corporais

No tema/eixo "termo dado", situam-se $72,6 \%$ dos textos analisados e utilizam o termo práticas corporais sem explicitar seu entendimento. Esta perspectiva constitui-se como majoritária neste tipo de material empírico e pode denotar a operação com o termo como se o mesmo se constituísse como um conceito estável, consensual e já consolidado.

Movimento, Porto Alegre, v. 16, n. 01, p. 11-29, janeiro/março de 2010. 
No tema/eixo "diferente de esporte", encontramos artigos com a expressão práticas corporais e esportivas, o que indica, por parte dos autores, a diferenciação de uma ou mais características entre práticas corporais e o esporte, sem que isso, contudo, fique claro no desenvolvimento do texto.

No tema/eixo "práticas corporais alternativas", encontra-se um tipo de crítica à sociedade moderna, em especial, às ocidentais, principalmente no que tange a exacerbação da racionalidade. Apresenta como saída ou possibilidade as práticas corporais alternativas que são entendidas como as de origem e/ou fundamentação oriental, da tradição dos povos ou de lógica divergente da formal. Essas práticas são exemplificadas como o taekwondo, a antiginástica, a biodança, a terapia reichiana, o tai-chi-chuan, a terapia corporal, a ginástica médica, a eutonia, além dos rituais, das meditações individuais ou coletivas, das terapias e das massagens.

Em "adjetivos diversos", os pesquisadores apresentam adjetivações para estas práticas corporais com intenção de complementar ou esclarecer o significado/sentido de seu uso. Como exemplos, encontramos: práticas corporais ativas e passivas, citadinas, lúdicas, polissêmicas e polimorfas, recreativas, negativas, escolares e infantis.

Já em "cultura corporal", os autores colocam práticas corporais como sinônimo de cultura corporal ou como expressão eleita para designar seus conteúdos, tais como ginástica, dança, lutas, esporte e jogos.

O tema/eixo "esporte" apresenta as modalidades esportivas como práticas corporais, de forma isolada e sem uma vinculação com os conceitos de cultura ou cultura corporal indicados anteriormente.

Em "cotidiano", as práticas corporais são entendidas por gestos mais simples e elementares como modos de vestir, de comer, de exercitar-se, de maquiar-se, de divertir-se, de cozinhar, de jogar, de cultivar o solo, de pescar, de caçar ou práticas de higiene, lembrando o conceito de técnicas corporais desenvolvido por Mauss (2003).

No tema/eixo "atividade física", os termos "práticas corporais" e "atividade física" são utilizados como sinônimos, apresentando in-

Wovimento, Porto Alegre, v. 16, n. 01, p. 11-29, janeiro/março de 2010. 
certeza ou indiferenciação quanto a seu uso. A incerteza pode ser percebida quando não se encontra referência na utilização de tal conceito e a indiferença quando colocam os dois termos como sinônimos, ao serem separados por barra. Alguns textos analisados apresentaram os dois termos citados, ou seja, em um mesmo texto, ocorreram momentos em que foi utilizado o termo práticas corporais e, em outros, apareceu "atividade física" sem diferenciá-los.

\subsection{TESES E DISSERTAÇÕES}

Foram recuperadas 26 teses e dissertações, sendo que destas, 17 foram analisadas por estarem disponíveis na íntegra para acesso livre. ${ }^{6}$ Nestas, o termo aparece pela primeira vez em Costa (1999). ${ }^{7}$ Na década de 1990, o termo aparece em apenas uma tese/dissertação, sendo que na década seguinte o termo aparece com mais expressividade, em 16 teses e dissertações.

\begin{tabular}{|l|c|}
\hline Campo de origem das teses e dissertações & Frequência \\
\hline Educação & 08 \\
\hline Educação Física & 03 \\
\hline Ciências Sociais Aplicadas & 02 \\
\hline Antropologia & 02 \\
\hline Artes & 01 \\
\hline Psicologia & 01 \\
\hline Total & 17 \\
\hline
\end{tabular}

Tabela 2 - Incidência do termo "Práticas Corporais" nas teses e dissertações brasileiras através da busca no BDTD do IBICT

As teses e dissertações que operam com o conceito de práticas corporais são todas vinculadas às ciências humanas e sociais e é no campo da Educação que aparece a maioria daquelas que utilizam o termo, num total de oito trabalhos. Em seguida, vem a Educação Física

\footnotetext{
${ }^{6}$ Vale destacar que foram analisadas somente as teses em formato texto, dado que as teses recuperadas no formato imagem não foram analisadas em função da impossibilidade de aplicar a técnica utilizada nos demais textos.

${ }^{7}$ Nos referimos à dissertação de doutorado em Educação Física intitulada "O corpo feminino no encontro com a antiginástica" de Elaine Melo de Brito Costa Lemos (1999).
}

Wovimento, Porto Alegre, v. 16, n. 01, p. 11-29, janeiro/março de 2010. 
com três e, com menor representatividade, a Psicologia, a Antropologia, as Ciências Sociais e as Artes, como pode ser observado na Tabela 2.

Das 17 teses e dissertações, apenas três apresentam o conceito de práticas corporais explicitamente, enquanto 14 usam o "termo como dado", na mesma direção expressa nos temas/eixo indicados na análise dos artigos.

Percebe-se que quando os autores conceituam o termo, fazem-no em duas perspectivas: como termo mais específico, encaminhando-se na direção da cultura corporal, como manifestações do tipo esporte, atividade física, exercício físico, jogo e dança e como termo genérico que designaria gestos e atividades cotidianas, como é o caso dos afazeres domésticos.

O termo práticas corporais, tal como foi encontrado nos periódicos, foi utilizado nas teses e dissertações com a intenção de problematizar os conceitos atividade física e exercício físico. Argumentam que estes conceitos encontram-se reduzidos à compreensão do movimento pela física clássica, enfatizando aspectos como a locomoção no tempo e no espaço e o gasto de energia. Enfatizam também a preocupação em incorporar aspectos subjetivos, como os sentidos e significados atribuídos pelos sujeitos e pela cultura ao movimento corporal humano.

Nas teses e dissertações analisadas, o autor mais citado é Marcel Mauss (2003) e os autores do campo da Educação Física referenciados para explicitar o conceito são: San'tanna (1995), Silva e Daminani (2005) e Carvalho (2006).

Dentre o material que não explicita o conceito, identificamos alguns sentidos para seu uso, tais como: a mímica e outras formas de expressão corporal; expressões corporais adquiridas ao longo da vida ou as espetacularizadas; práticas corporais culturalmente criadas e expressas através dos gestos corporais; representações corporais; práticas corporais de academias; autocuidado; culto ao corpo; representações e símbolos expressos pelo sujeito; atividade sistemática de intervenção no corpo biológico; exercitação corporal; body art; cuidados com o corpo e relaxamento. Percebe-se que, diferente dos periódicos onde a predominância dos artigos que fazem uso do termo situa-se

Movimento, Porto Alegre, v. 16, n. 01, p. 11-29, janeiro/março de 2010. 
no campo Educação Física, as teses e dissertações estão vinculadas aos outros campos das humanidades, o que talvez possa explicar melhor a diferenciação que se mostra nos sentidos e na amplitude na utilização do termo.

\section{ANÁLISE E dISCUSSÃo}

A partir do material empírico analisado - artigos, teses e dissertações -, podemos afirmar que o termo "práticas corporais" vem sendo operado por vários campos do conhecimento, sendo que dentre estes a Educação Física é o que o utiliza com maior frequência. Nos campos da Educação, da Antropologia, da Sociologia, da Psicologia, da História e da Saúde, seu uso também é relativamente frequente, porém com diferentes significados/sentidos.

Na medida em que o termo é relacionado com a saúde, aparecem preocupações com os cuidados com o corpo. Nestes termos, as práticas corporais entram como complementares aos cuidados convencionais, trazendo elementos da cultura oriental, como é o caso da meditação, do relaxamento e de práticas milenares. Em certa medida, esta também é a ênfase do campo da Psicologia, enfatizando um olhar terapêutico para com as práticas corporais, ainda que as compreendendo como engendradas por tensões e conflitos pessoais e em determinadas sociedades.

$\mathrm{Na}$ Educação, o termo práticas corporais parece ser relevante e é recorrente neste tipo de produção acadêmica. Nos documentos analisados, destacamos que parte dessa produção é oriunda dos pesquisadores da própria Educação Física que ali desenvolvem seus estudos ou publicam em periódicos daquele campo. Este aspecto mereceria uma investigação mais detalhada, inclusive porque há, historicamente, uma relação estreita entre a Educação Física, seus conceitos e práticas, e aqueles provenientes da Educação.

A Antropologia parece operar com o termo compreendendo-o, predominantemente, como sinônimo de técnicas corporais, principalmente tendo por base o clássico estudo de Mauss (2003). Aparecem, porém, menções a técnicas extremamente diversas, desde aquelas mais

Wovimento, Porto Alegre, v. 16, n. 01, p. 11-29, janeiro/março de 2010. 


\section{4}

elementares que são parte do cotidiano, até aquelas mais complexas e elaboradas, como o body art e o esporte. Há menção, ainda, de técnicas corporais específicas de determinadas populações e grupos sociais, como é o caso dos indígenas, crianças em situação de rua, trabalhadores rurais, entre outros.

De maneira geral, nota-se que o termo "práticas corporais" vem aparecendo na maioria dos textos como uma expressão que indica diferentes formas de atividade corporal ou de manifestações culturais, tais como: atividades motoras, de lazer, ginástica, esporte, artes, recreação, exercícios, dietas, cirurgias cosméticas, dança, jogos, lutas, capoeira e circo.

Estes movimentos ou atividades vão desde as mais tradicionais (práticas adestradoras; precisas e sistematizadas de marcante caráter racional e higiênico; competitivas; práticas corporais mais remotas), até as ressignificadas, indicando ou não uma relação com a Educação Física (práticas corporais diárias; cotidianas; humanas; na maternidade; de diferentes culturas e ocidentais e orientais).

Os pesquisadores apresentaram, muitas vezes, algum adjetivo para especificar o objeto de estudo que está sendo tratado. Acompanhando o termo práticas corporais, identificamos palavras como: escolares; lazer; indígenas; aventura na natureza; entretenimento; lúdicas; autoconhecimento e alternativas.

Quanto às contribuições dos pesquisadores que ajudam a conceituar práticas corporais, percebemos algumas indicações de uma outra perspectiva ontológica e seu desdobramento em uma compreensão de corpo que se opõe ao biologicismo. Ressaltamos, inclusive, que a expressão "não só biológica" é recorrente nos textos pesquisados, representando uma primeira etapa caracterizada pela negação, característica no processo de conceituação. No entanto, aquilo que caracterizaria a afirmação do conteúdo do conceito, as tentativas de conceitualização, não são recorrentes no material analisado.

A preocupação com os significados/sentidos atribuídos às práticas corporais por parte dos sujeitos que as praticam foi frequente no material analisado, demonstrando uma preocupação em considerar os conteúdos subjetivos postos em ação, para além do pragmatismo

Movimento, Porto Alegre, v. 16, n. 01, p. 11-29, janeiro/março de 2010. 
presente num raciocínio causal. Esta preocupação aparece aliada a outro forte componente, talvez o principal, que seja a consideração pelas práticas corporais como elemento da cultura, manifestações culturais que se explicitam principalmente na dimensão corporal.

Essa amplitude do entendimento de práticas corporais caminha na direção da tese defendida por Krieger (2006), de que campos, setores e áreas novas das humanidades possuem dificuldade em trabalhar com conceitos fechados por conta da própria natureza de seu objeto de reflexão. Pode ser decorrente desta condição, a ampliação de seu espectro de entendimento e utilização do conceito, correndo o risco, inclusive, deste confundir-se com seu uso no senso comum ou assumindo diferentes significados/sentidos.

\section{CONSIDERAÇõES FINAIS}

Toda a representação conceitual é uma delimitação arbitrária que, em certa medida, indica sentidos ao mesmo tempo em que conforma práticas sociais, determinando como os sujeitos deles se apropriam. O esforço de reflexão se faz necessário para que uma dada comunidade, que opera com termos e conceitos, possa dialogar sobre formas de representação comuns.

Identificamos nos textos analisados que o termo "práticas corporais" já se constitui com potencialidade para ser estruturado como conceito, necessitando, porém, de maior estabilidade e de um certo nível de consenso dentre a comunidade acadêmica. Ainda que provisório, um acordo entre os pesquisadores a partir do exercício conceitual, mesmo restrito a um determinado campo ou parcela significativa de uma comunidade acadêmica, faz-se necessário para obter conceitos comuns que melhor abarquem um dado da realidade e que permitam sua ampliação posterior.

No campo da Educação Física, o termo "práticas corporais" vem sendo valorizado pelos pesquisadores que estabelecem relação com as ciências humanas e sociais, pois aqueles que dialogam com as ciências biológicas e exatas operam com o conceito de atividade física. Esta dualidade parece ser um grande entrave ou, talvez, apresente-se

Movimento, Porto Alegre, v. 16, n. 01, p. 11-29, janeiro/março de 2010. 


\section{6}

como uma potencialidade, pela interface que a Educação Física estabelece com as ciências humanas e sociais e com as ciências biológicas e exatas. Esta interface, ao mesmo tempo que dificulta as relações e os consensos mínimos, também exige criatividade, reflexão e autoavaliação constantes. É justamente nesta busca por saídas no processo de construção de sua própria especificidade, para além das demarcações disciplinares tradicionais e dos encaminhamentos da política científica oficial que se inscreve o presente texto. Um desafio que pensamos dever ser enfrentado coletivamente, sobretudo por aqueles que compreendem a impossibilidade de abrir mão da complexidade deste campo e dos objetos de estudo a serem enfrentados.

A maioridade acadêmica aludida anteriormente, a qual a Educação Física tanto busca, exigirá permanente debate acerca dos conceitos com os quais opera e com os quais expressa os significantes que problematiza, sendo reconhecidos por seus pares para pensar a Educação Física. Talvez esta maioridade possível não esteja vinculada à concepção de ciência tradicional e suas demarcações disciplinares e, sim, como campo acadêmico diferenciado que construirá saídas nos limites e interlocuções entre as ciências biológicas, exatas, humanas e sociais ao enfrentar os problemas postos pela realidade e por suas necessidades de intervenção social.

Movimento, Porto Alegre, v. 16, n. 01, p. 11-29, janeiro/março de 2010. 


\begin{abstract}
The term "Body Practices" in scientific literature and its repercussion in the Physical Education field.

Abstract: The aim is to identify the meanings/senses by which the term "body practices" has been used in the Brazilian academic literature, parting from the analysis of the content of 260 articles and 17 thesis/dissertations, found by the use of keywords through search systems and data base. The results indicate that: the use of the term enhances after the year 2000; the researches that utilize it, mostly develop their research in interface with human sciences; in most of the documents there is no concern about the concept definition; there are several meanings/senses. The data also indicates that the term has not reached a stable concept, despite being gathering elements for that.

Keywords: Exercise movement techniques. Physical Education. Concept formation.
\end{abstract}

\begin{tabular}{|l|}
\hline La expresión "Prácticas Corporales" en la lite- \\
ratura científica brasileña y su repercusión en \\
el campo de la Educación Física \\
Resumen: Se objetivó identificar los significados/sen- \\
tidos con los quales la expresión prácticas corporales \\
viene siendo utilizada en la literatura académica brasileña, \\
mediante analice de contenido de 260 artículos y 17 \\
tesis/disertaciones que han sido capturadas con el uso \\
de palabras claves en sistemas de busca y bases de \\
datos. Los resultados indican que: su utilización es in- \\
tensificada después del año 2000; los pesquisadores \\
que lo utilizan, predominantemente, desarrollan sus inves- \\
tigaciones en interacción con las humanidades; en la la \\
mayoría de los documentos no hay un preocupación de \\
definición conceptual; presenta varios significados/ \\
sentidos. Los datos indican aún no ter atingido estabilidad \\
como concepto, aunque estea cumulando elementos \\
para tal. \\
Palabras clave: Técnicas por movimiento de ejercicio. \\
Educación Física. Formación de concepto.
\end{tabular}

\title{
REFERÊNCIAS
}

BARDIN, Laurence. Análise de conteúdo. Lisboa: Edições 70, 1979.

BETTI, Mauro. Por uma teoria da prática. Motus Corporis, Rio de Janeiro, v.3, n.2, p.73-127, 1996.

Movimento, Porto Alegre, v. 16, n. 01, p. 11-29, janeiro/março de 2010. 


\section{Astifor Orifinais Ari Lazzarotti Filho et al.}

BRACHT, Valter. Educação Física \& Ciência: cenas de um casamento (in)feliz. ljuí: UNIJUÍ, 1999.

Sociologia crítica do esporte. 2. ed. rev. ljuí: UNIJUí, 2003.

CARVALHO Yara Maria de. Promoção da saúde, práticas corporais e atenção básica. Revista Brasileira de Saúde da Família, Brasília, v. 7, p. 33-45, 2006.

CAMPOS, Maria Luiza de; SOUZA, Rosely Fernandez; CAMPOS, Maria Luiza Machado. Organização de unidades de conhecimento em hiperdocumentos: o modelo conceitual como espaço comunicacional para a realização da autoria. Ciência da Informação, Brasília, v. 32, n. 2, p. 7-16, 2003.

COSTA, Elaine Melo de Brito. O Corpo Feminino no Encontro com a Antiginástica, 1999. 217 f. Dissertação (Mestrado) - Curso de Educação Física, Unicamp, Campinas, 1999.

DAHLBERG, Ingetraut. Teoria do conceito. Ciência da Informação, Brasília, v.7, n.2, p. 101-07, 1978.

FENSTERSEIFER, Paulo Evaldo. O que significa aprender no âmbito da cultura corporal de movimento. 2008. (manuscrito).

FERREIRANETO, Amarílio. Leituras dos 20 e 25 anos do CBCE: política, comunicação e (in)definição do campo científico. In: LEITURAS da natureza científica do Colégio Brasileiro de Ciências do Esporte. Campinas: Autores Associados, 2005.

FRAGA, Alex Branco. Concepções de gênero nas práticas corporais de adolescentes. Movimento, Porto Alegre, v. 2, n. 31995.

GOMES, Christianne Luce (Org.). Dicionário crítico do lazer. Belo Horizonte: Autêntica, 2004

LOVISOLO, Hugo. Pós-Graduação e Educação física: paradoxos, tensões e diálogos. Revista Brasileira de Ciências do Esporte, Florianópolis, v.20, n.1, p.11-21, 1998

GONZÁLEZ, Fernando; FENSTERSEIFER, Paulo Evaldo. (Org.). Dicionário crítico de Educação Física. ljuí: Ed. UNIJUÍ, 2005.

LE GUERN, Michel; Sur les relations entre terminologie et lexique. Meta, Montreal, v.34, n.3, p. $340-343,1989$

MUGNAINI, Rogério, POBLACIÓN, Dinah. Impacto de documentos citados em Revistas cientificas brasileiras de diferentes áreas. In. ENCONTRO NACIONAL DE PESQUISA EM CIÊNCIA DA INFORMAÇÃO, 7., Salvador, 2007. Anais... Salvador, 2007. v. 8.

MAUSS, Marcel. Sociologia e antropologia. São Paulo: Cosac \& Naify, 2003.

MELO, Victor Andrade de. Dicionário do Esporte no Brasil. São Paulo: Autores Associados, 2007.

Wovimento, Porto Alegre, v. 16, n. 01, p. 11-29, janeiro/março de 2010 
PAIVA, Fernanda Simone Lopes de. Notas para pensar a Educação Física a partir do conceito de campo. Revista Perspectiva, Florianópolis, v. 22, n. Especial, p. 51-82, jul./dez. 2004.

KRIEGER, Maria da Graça. Terminologia técnico-científica: políticas linguísticas e mercosul. Ciência e Cultura, São Paulo, v. 58, p.45-48, 2006.

SANT'ANNA, Denise Bernuzzi. (Org.). Políticas do corpo: elementos para uma história das práticas corporais. São Paulo: Estação Liberdade, 1995.

SILVA, Ana Márcia. Uma Política Científica para a Educação Física ou de Alice e a Toca do Coelho. In: CARVALHO, Yara Maria de; LINHALES, Meily Assbú. (Org.). Política científica e produção do conhecimento. Goiânia: Editora da UFG, 2007.

SILVA, Ana Marcia; DAMIANI, lara Regina. As práticas corporais na contemporaneidade: pressupostos de um campo de pesquisa e intervenção social. In: SILVA, Ana Marcia; DAMIANI, lara Regina. (Org.). Práticas corporais: gênese de um movimento investigativo em Educação Física. Florianópolis: Naemblu Ciência e Arte, 2005. p.17-28.

SMOLKA, Ana Luiza Bustamante. O (im)próprio e o (im)pertinente na apropriação das práticas sociais. Caderno Cedes, Campinas, v.20, n.50, p.26-40, abr. 2000.

TANI, Go. Cinesiologia, educação física e esporte: ordem emanante do caos na estrutura acadêmica. Motus Corporis, Rio de Janeiro, v.3, n.2, p.9-50, 1996.

VAZ, Alexandre Fernandez. Educação do corpo, conhecimento, fronteiras. Revista Brasileira de Ciências do Esporte, Campinas, v.24, n.2, p.161-172 jan. 2000.

Movimento, Porto Alegre, v. 16, n. 01, p. 11-29, janeiro/março de 2010. 